\title{
Advanced Protection Against Marine Biofouling Using Solar Light
}

Gabriele Scandura, Rosaria Ciriminna, Lütfiye Yıldız Ozer, ${ }^{\prime}$ Francesco Meneguzzo, ${ }^{3}$ Giovanni Palmisano, ${ }^{*}$ Mario Pagliaro ${ }^{{ }^{*}}$

${ }^{1}$ Department of Chemical and Environmental Engineering, Masdar Institute of Science and Technology, PO BOX 54224, Abu Dhabi, United Arab Emirates; ${ }^{2}$ Istituto per lo Studio dei Materiali Nanostrutturati, CNR, via U. La Malfa 153, 90146 Palermo, Italy; ${ }^{3}$ Istituto di Biometeorologia, CNR, via Caproni 8, 50145 Firenze, Italy

\begin{abstract}
We undertook prolonged testing of a new xerogel coating (AquaSun) to protect from marine biofouling a surface probe immersed in the seawater of Abu Dhabi. Electron microscopy, Raman mapping, and photoluminescence experiments coupled to extensive analyses of marine water before and after 122 days of testing showed excellent action against biofouling when irradiating the probe with visible light. Considering the high chemical and mechanical stability and the low cost of the sol-gel coating, the technology has significant potential en route to replacing conventional antifouling and foul release coatings with a single product of broad applicability.
\end{abstract}

Keywords: antifouling; sol-gel; photocatalytic; ecofriendly coating.

\author{
*Corresponding Authors \\ Dr. M. Pagliaro \\ Istituto per lo Studio dei Materiali Nanostrutturati, CNR \\ via U. La Malfa 55 \\ 9oi46 Palermo (Italy) \\ E-mail: mario.pagliaro@cnr.it
}

Dr. G. Palmisano

Department of Chemical and Environmental Engineering

Masdar Institute of Science and Technology

PO BOX 54224, Abu Dhabi (United Arab Emirates)

E-mail: gpalmisano@masdar.ac.ae 


\section{Introduction}

Every year, more than 8o,ooo tonnes of marine antifouling (AF) paints, mostly copper-based, are used across the world to protect vessels of any size and scope, posing a serious threat to the environment. Intense researches carried out at both antifouling coating makers and in academic research centres has actually resulted in the development of several environmentally benign alternatives, mostly based on foul-release polymeric coatings, but including also formulations, whose action is based on less toxic biocides. ${ }^{2}$ Foul-release $(\mathrm{FR})$ waterborne xerogel coatings comprised of organically modified silica (ORMOSIL) are amongst the environmentally benign solutions identified. ${ }^{3}$ Their action is based on the ability to form a thin hydrophobic protective layer to which biofouling sticks loosely to be released even at low cruising speed. Their main limitation is due to their limited antifouling action when the vessel is still in harbor for prolonged periods.

Aiming to develop a coating capable to provide full protection to ships, recreational boats and underwater structures against marine biofouling, we have recently reported the promising discovery that nanoflower-like $\mathrm{Bi}_{2} \mathrm{WO}_{6}$ encapsulated in methyl-modified silica shows excellent photocatalytic antifouling action leading to formation of hydrogen peroxide. ${ }^{4}$ Hydrogen peroxide is a strong and clean oxidant decomposing into water and oxygen, ${ }^{5}$ able to rapidly degrade the (bio)organic species adsorbed onto the film making the surface inhospitable to the settling larvae of fouling organisms, by a free-radical intermediate that prevents the attachment of hard foulants. ${ }^{6}$ 
Dubbed AquaSun, such coating typically forms a transparent thin film (3 $\mu \mathrm{m}$ thick) of methylsilica in which the particles of the semiconductor are homogeneously encapsulated within the ORMOSIL matrix, retaining their flower-like nanostructure. Using uracil as representative molecular precursor of biofouling, we showed that under irradiation with solar light, the coating degraded about half of I ppm uracil in three days. No wolframate leaching was observed into the supernatant solution, even after three months immersion, and after repeated irradiation cycles. Remarkably, furthermore, the activity degradation rate was found to be linear, pointing to no saturation effects or prolonged absorption of the substrate. Indeed, further investigation using adenine as probe revealed good foul release properties of the coating, with all adenine adsorbed from a I ppm solution being released in 2 hours upon immersion in water, even in the absence of light irradiation. Now, we show the efficiency of this new coating in real life tests conducted for 122 days in sea water withdrawn from Al Raha Beach, Abu Dhabi, United Arab Emirates. 


\section{Results and Discussion}

The waterborne coating was sol-gel derived through hydrolytic polycondensation, in acidic conditions, of a sol containing 5o mol \% tetraethoxysilane (TEOS) and 5o mol \% methyl-triethoxysilane (MTES) to which flower-like nanostructured $\mathrm{Bi}_{2} \mathrm{WO}_{6}$ was added $(50 \mathrm{mM})$ as previously described. ${ }^{4}$ Runs were performed in a $2.5 \mathrm{~L}$ beaker, by using sea water ( $1.5 \mathrm{~L}$ ) placed in contact with glass slides after getting rid of most sand particles through sedimentation. Bare and functionalized glass slides were used in two different conditions: (A) no applied radiation, meaning that only the low diffuse radiation present in the laboratory reached the solution; and (B) under intermittent irradiation with 5oo W simulated solar light. In the latter case, water evaporation was not negligible. Consequently, an aliquot of sea water (around roo $\mathrm{mL}$ ) was poured in the beaker to replenish the original amount around every to days since the beginning of the experiment. The overall experiment lasted ı22 days.

Table 1. Irradiation time under simulated solar light for experiment B.

\begin{tabular}{llll}
\hline Period & Hours per day & Number of days & Total hours of irradiation \\
\hline From day I to day 42 & 2.5 & 42 & 105 \\
From day 43 to day 65 & 8.5 & 23 & 195.5 \\
From day 66 to day I22 & 5 & 57 & 285 \\
\hline
\end{tabular}

In experiment $\mathbf{B}$ the radiation intensities were $2.8 \mathrm{~W} / \mathrm{m}^{2}$ in the range $3 \mathrm{I} 5$-40o $\mathrm{nm}$ and $60 \mathrm{~W} / \mathrm{m}^{2}$ in the range $450-950 \mathrm{~nm}$. Irradiation was applied every day for the 
number of hours indicated in Table I total number of hours under simulated solar light was 585.5).

Figure I and Figure 2 show, respectively, the visible light radiation intensity (wavelength range: 400-1050 $\mathrm{nm}$ ) in the laboratory during a working day, and the visible light irradiation intensity (wavelength range: 400-1050 $\mathrm{nm}$ ) in the laboratory during a public holiday. Radiation intensity was measured with a Delta Ohm 972I radiometer and the matching probes.

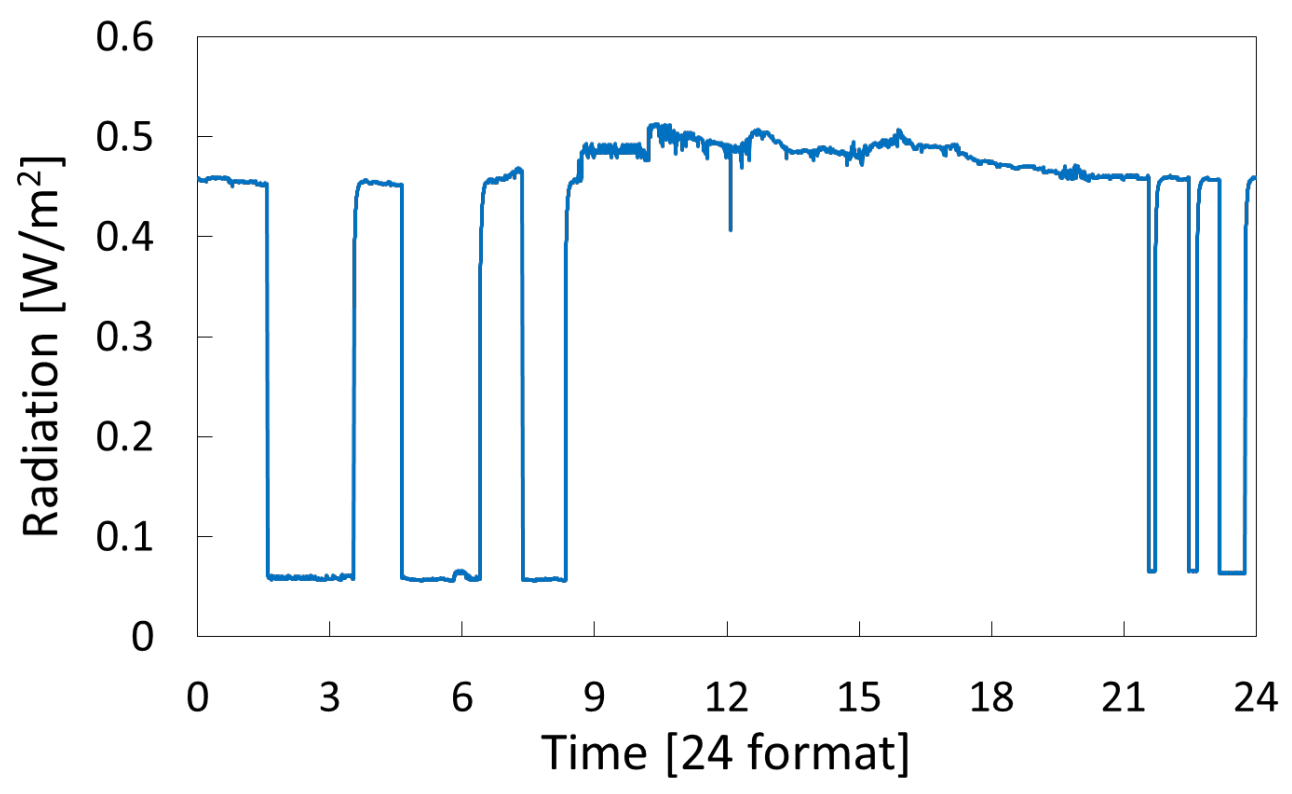

Figure 1. Radiation intensity (wavelength range: 400-1050 nm) in the laboratory during a working day. 
bioRxiv preprint doi: https://doi.org/10.1101/106195: this version posted Februarv 6. 2017. The copvriaht holder for this preprint (which was not certified by peer review) is the author/funder, who has granted bioRxiv a license to display the preprint in perpetuity. It is made available under aCC-BY-NC 4.0 International license.

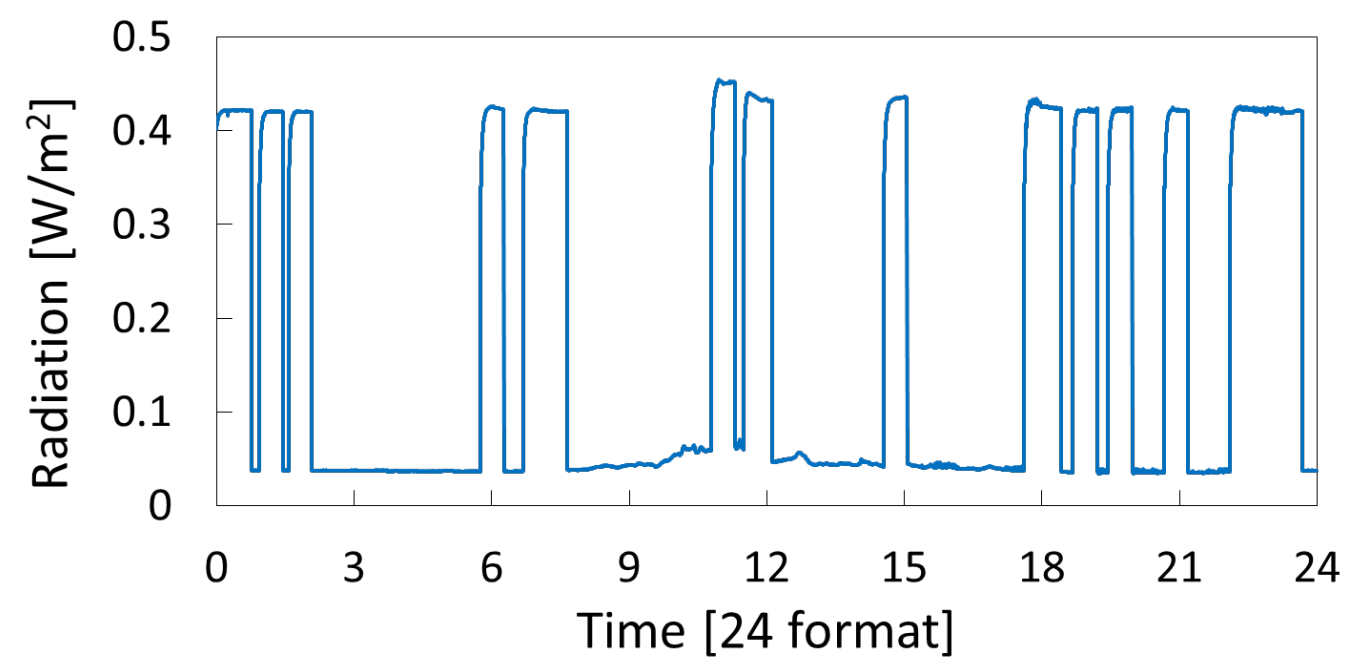

Figure 2. Radiation intensity (wavelength range: 400-1050 nm) in the laboratory during a public holiday. 
Characteristics of the sea water were analyzed with a Shimadzu TOC-L Total

Organic Carbon analyzer, a Delta Ohm pH- $\chi-\mathrm{O}_{2}$ meter $(\bmod$. HD22569.2), an Ion

Chromatography System Dionex ICS-5ooo and a HACH 2IooAN turbidimeter.

Table 2 and Table 3 summarize the characteristics of the sea water at the

beginning (day o) and at the end (day 122) of the experiments.

Table 2. Main characteristics of the sea water at the beginning $($ day $=0$ ) and at the end $($ day $=122)$ of the experiment.

\begin{tabular}{|l|l|l|l|}
\cline { 2 - 4 } \multicolumn{1}{c|}{} & Day 0 & Day 122 experiment A & Day 122 experiment B \\
\hline $\mathrm{pH}$ & 8.250 & 8.483 & $8.19 \mathrm{I}$ \\
\hline Conductivity $[\mathrm{mS}]$ & 50.4 & 53.6 & 64.5 \\
\hline Dissolved O $[\mathrm{mg} / \mathrm{L}]$ & 7.73 & 7.53 & 7.43 \\
\hline TC $[\mathrm{mg} / \mathrm{L}]$ & 26.60 & 26.76 & 25.72 \\
\hline IC $[\mathrm{mg} / \mathrm{L}]$ & 25.38 & 25.57 & 22.93 \\
\hline TOC $[\mathrm{mg} / \mathrm{L}]$ & 1.218 & 1.186 & 2.784 \\
\hline Turbidity $[\mathrm{NTU}]$ & 0.130 & 0.226 & 0.407 \\
\hline
\end{tabular}

$\mathrm{TC}=$ total carbon, $\mathrm{IC}=$ inorganic carbon, $\mathrm{TOC}=$ total organic carbon

Table 3. Ions concentrations expressed in $\mathrm{mg} / \mathrm{L}$ in the sea water at the beginning $($ day $=0)$ and at the end $($ day $=122)$ of the experiment.

\begin{tabular}{|c|c|c|c|}
\hline & Day 0 & Day 122 experiment $A$ & Day 122 experiment $B$ \\
\hline $\mathrm{Na}$ & $\mathrm{I} 3,400$ & 14,200 & 30,200 \\
\hline K & 3,300 & 3,570 & 6,700 \\
\hline $\mathrm{Mg}$ & ı 69.5 & I83.5 & 348 \\
\hline $\mathrm{Ca}$ & 422 & 457 & 845 \\
\hline $\mathrm{Li}$ & traces & traces & traces \\
\hline $\mathrm{NH}$ & 4.4 & 4.9 & 5.0 \\
\hline $\mathrm{Cl}$ & 28,200 & 29,700 & 60,000 \\
\hline $\mathrm{Br}$ & 97.5 & 104 & 192.5 \\
\hline $\mathrm{NO}$ & 2.45 & I. 43 & 3.15 \\
\hline $\mathrm{SO}$ & 3,970 & 4,180 & 8,870 \\
\hline $\mathrm{F}$ & І. 35 & I. 40 & 2.40 \\
\hline
\end{tabular}


Under solar light, marine phytoplankton microorganisms give place to photosynthesis providing organic matter for the organisms that comprise the majority of marine life, ${ }^{7}$ consuming inorganic carbon. For this reason, in the experiment B the total organic carbon (TOC) increased and the inorganic carbon (IC) decreased when comparing the initial and final concentrations. Nevertheless, the total carbon $(\mathrm{TC})$ is reduced because the thin film under visible light is able to mineralize organic matter with formation of carbon dioxide which evolves from the supernatant solution. ${ }^{\mathrm{I}}$

Conversely, in experiment $\mathbf{A}$, the values of TC, IC, and TOC before and after each run are substantially the same, which is due to the insufficient radiation, thereby proving that degradation is due to the photocatalytically formed hydrogen peroxide achievable only by irradiating with (simulated) solar light. When the film is applied on a surface constantly exposed to solar radiation, it continuously produces $\mathrm{H}_{2} \mathrm{O}_{2}$ according to Equations $\mathrm{I}-5$, where $\mathrm{h}^{+}$are the holes generated in the valence band of the semiconductor and $\mathrm{e}^{-}$are the electrons formed in the conduction band: ${ }^{8}$

$$
\begin{aligned}
& \mathrm{Bi}_{2} \mathrm{WO}_{6}+\mathrm{hv} \rightarrow \mathrm{Bi}_{2} \mathrm{WO}_{6}\left(\mathrm{e}^{-}(\mathrm{CB})\right. \\
& \left.\mathrm{OH}-+\mathrm{h}_{(\mathrm{VB})}^{+}\right) \\
& \mathrm{O}_{2}^{+}+\mathrm{e}^{-}{ }_{(\mathrm{CB})} \rightarrow \mathrm{OH}_{2}^{--} \\
& \mathrm{O}_{2}^{--}+\mathrm{H}^{+} \rightarrow \mathrm{HO}_{2} \cdot \\
& 2 \mathrm{HO}_{2} \rightarrow \mathrm{O}_{2}+\mathrm{H}_{2} \mathrm{O}_{2}
\end{aligned}
$$


Diffuse reflectance spectra were measured by UV-Vis spectrophotometer (Shimadzu UV-26oo) in the range 35o-75o nm. Comparison between the UV-vis diffuse reflectance spectra of the bare glass slide and the glass slide functionalized with the AquaSun coating (Figure 3) highlights a minor shift of the latter since, under simulated solar light, the film functionalized with the coating is much cleaner than the unprotected glass.

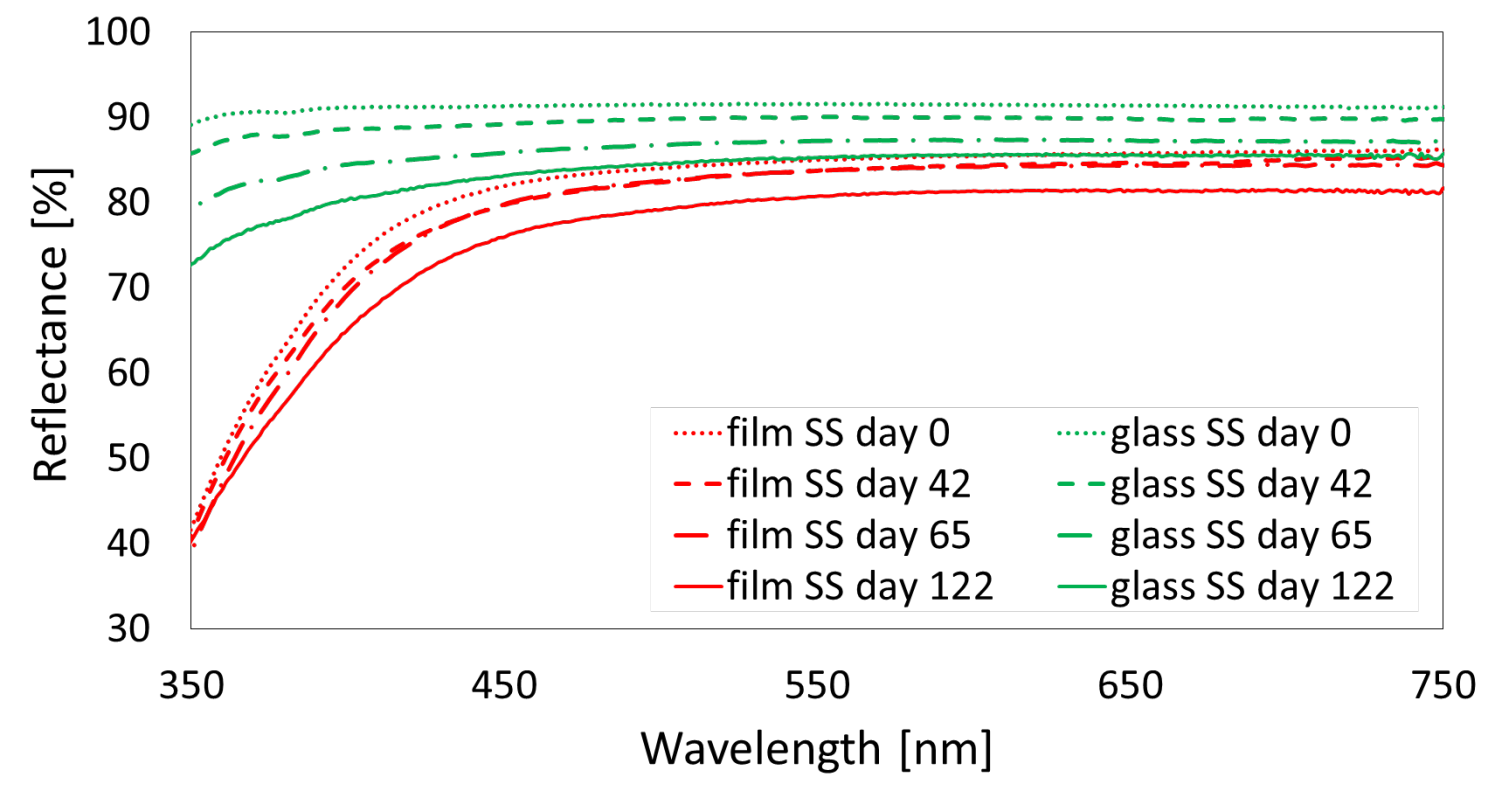

Figure 3. Diffuse reflectance spectra of bare glass and functionalized glass (labelled as "film") in the presence of simulated solar light. SS stands for "solar simulator" and it refers to the experiment B. 


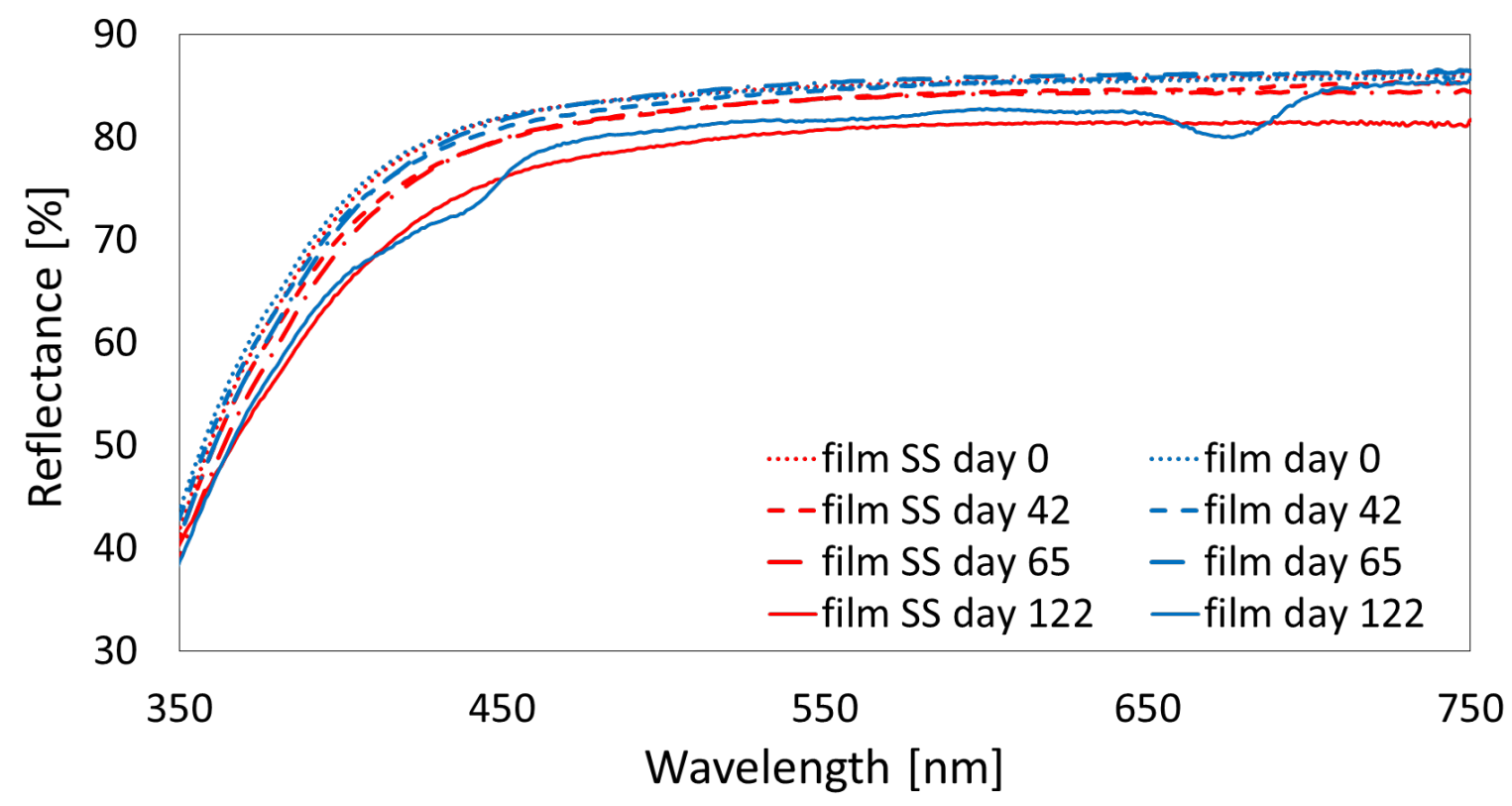

Figure 4. Diffuse reflectance spectra of functionalized glass (labelled as "film") in the absence or in the presence of simulated solar light. SS stands for "solar simulator" and it indicates the experiment $\mathbf{B}$.

The effect of the solar light on the glass slide functionalized with the AquaSun thin film is evident from Figure 4 showing that the coated glass, when exposed to the low diffuse radiation present in the laboratory room, undergoes the growth of biomass on its surface. because after 4 months (day 122) two significant peaks (around 440 and $675 \mathrm{~nm}$ ) appear in the diffuse reflectance spectrum. Accordingly, the TC, IC and TOC values at the end of the test in sea water did not decrease: a crucially important result that was visually confirmed (see photograph in Figure $5)$. 


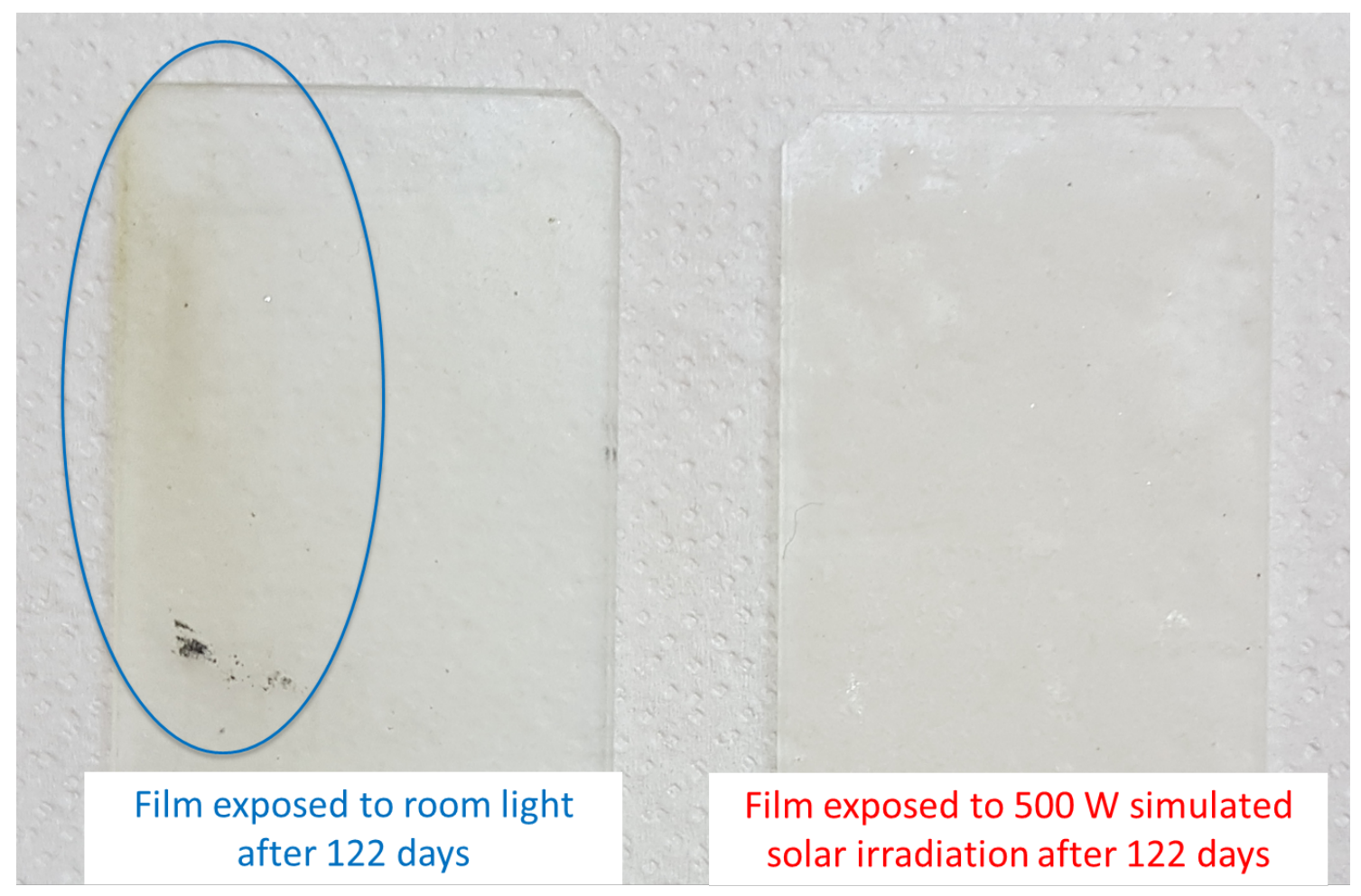

Figure 5. The blue oval indicates the area of the film where a biomass layer deposited because of the low irradiation.

The presence of the biomass also affects the photoluminescence (PL) of the film. The spectra in emission mode with an excitation at $300 \mathrm{~nm}$ were recorded using a Perkin Elmer LS 55 spectrometer between 3ıo and $600 \mathrm{~nm}(200 \mathrm{~nm} / \mathrm{min}$ scan rate). The PL spectrum of the functionalized glass shows a peak around $420 \mathrm{~nm}$ (Figure 6) which is clearly stronger when the film was exposed to room light in comparison to the peak shown by the coated glass exposed to simulated solar irradiation. Indeed, it is known that some marine microorganisms such as algae can produce photoluminescence emission in the visible region due to the proteins or aromatic amino acid, and their metabolites. ${ }^{9}$ 


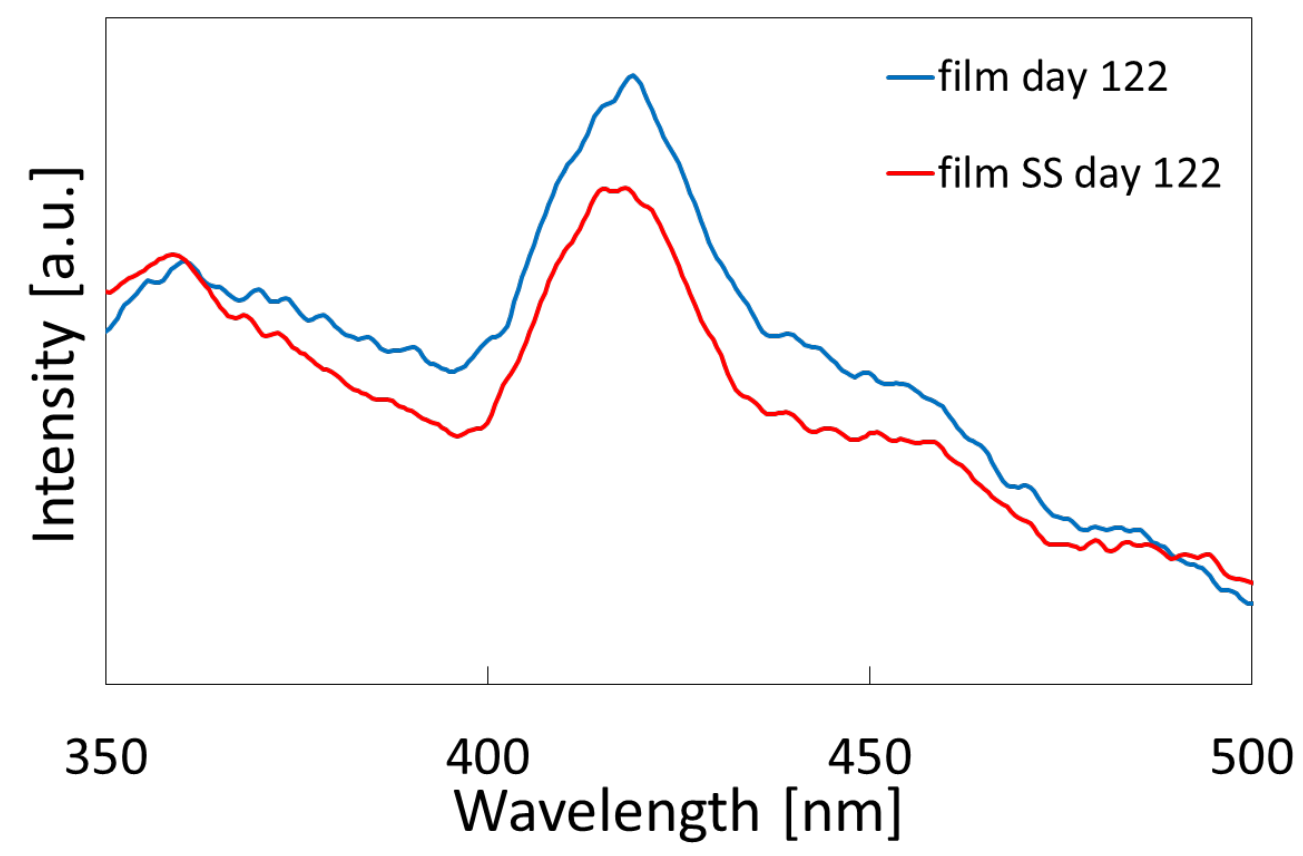

Figure 6. The photoluminescence (PL) spectra of functionalized glass (labelled as "film") with an excitation of $300 \mathrm{~nm}$ in the absence or in the presence of simulated solar light. "SS" stands for "solar simulator" and it refers to experiments $\mathbf{B}$.

Figure 7 depicts the Raman spectra of both bare and functionalized glass before (day o) and after the experiments (day 122), recorded with a Witec Alpha 3ooR equipment, with an excitation wavelength of $532 \mathrm{~nm}$ and a laser power of ca. 75 $\mathrm{mW}$. Scans were taken over an extended range $\left(\right.$ Ioo-20oo $\left.\mathrm{cm}^{-1}\right)$ with $5 \mathrm{~s}$ integration time and 30 accumulations. Raman mapping was done with o.I s integration time. 


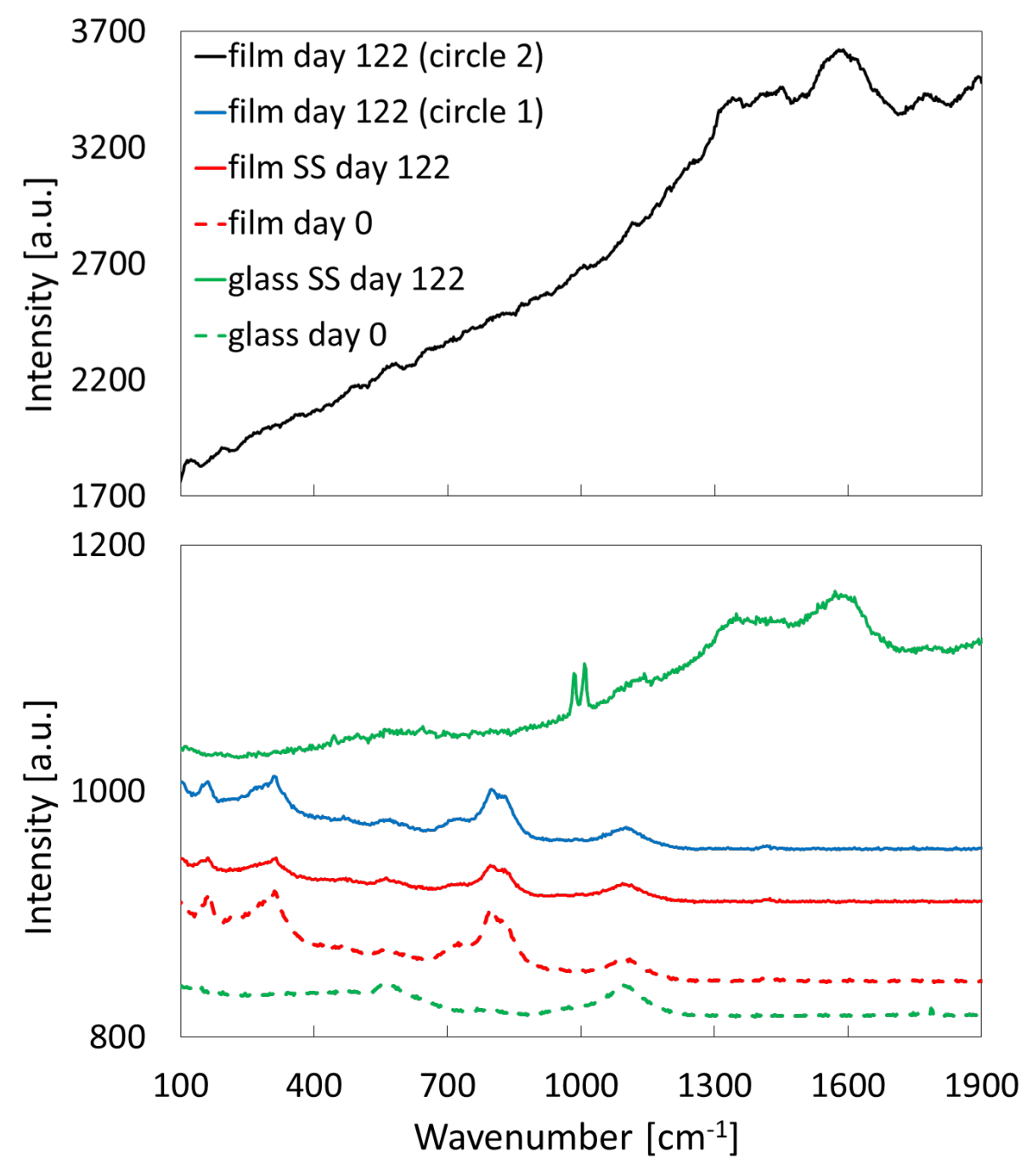

Figure 7. Raman spectra of functionalized (labelled as "film") and bare glass before (day o) and after I22 days in the absence or in the presence of simulated solar light. "SS" stands for "solar simulator" and it refers to experiments B. The curves related to the 'film day I22' were obtained by pointing Raman laser on the circles I and 2 in Figure 8a.

The glass coated with AquaSun coating exhibits three peaks (at ca. I6I, 3II, and $799 \mathrm{~cm}^{-\mathrm{I}}$ ) attributable to $\mathrm{Bi}_{2} \mathrm{WO}_{6}$ encapsulated in the ORMOSIL, ${ }^{\text {,o }}$ and two peaks (around 560 and $1095 \mathrm{~cm}^{-1}$ ) due to the glass substrate.

In experiment $\mathbf{B}$, the functionalized film after four months shows the same Raman spectrum as day $=0$. On the contrary the bare glass spectrum displays 
bioRxiv preprint doi: https://doi.org/10.1101/106195; this version posted February 6, 2017. The copyright holder for this preprint (which was not certified by peer review) is the author/funder, who has granted bioRxiv a license to display the preprint in perpetuity. It is made available under aCC-BY-NC 4.0 International license.

several new peaks. The film of the experiment $\mathbf{A}$ affords two different types of spectra according to where the laser beam is pointed. One (corresponding to circle $\mathrm{I}$ in Figure 8a) is identical to the spectrum at day $=0$. Another (corresponding to circle 2 in Figure 8a) displays a much larger background intensity (top curve in Figure 7). This spectrum results from biomass which has been produced because of the poor illumination in the room, and is caused by the photoluminescence of the biomass itself (in agreement with Figure 6), which covers completely the signals of $\mathrm{Bi}_{2} \mathrm{WO}_{6}$.

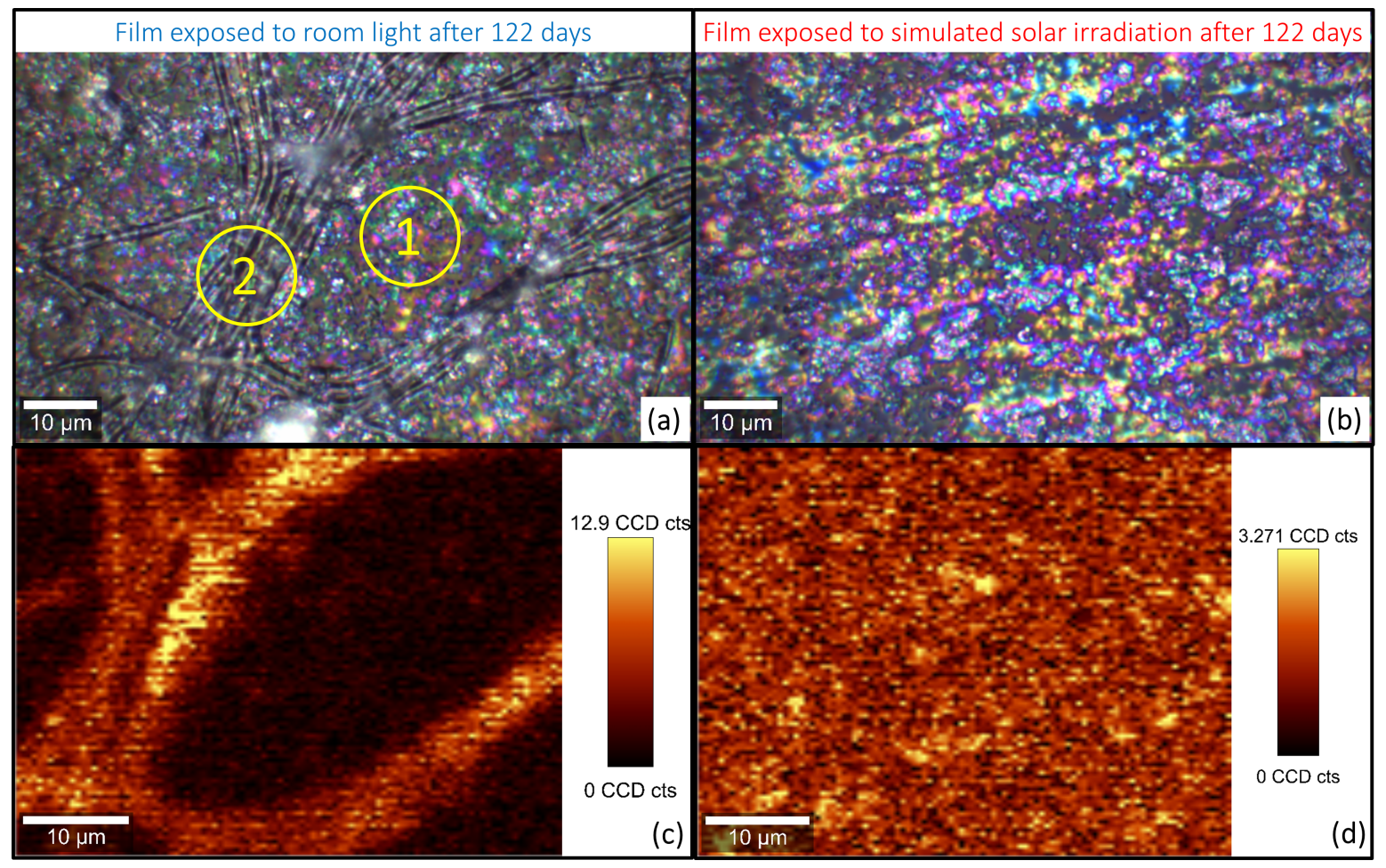

Figure 8. Ioox magnified optical images of the films after 122 days in the absence (a) or in the presence of simulated solar light (b). $799 \mathrm{~cm}$ peak Raman mapping (c, d) corresponding to the images above respectively. Circles $\mathrm{I}$ and 2 indicate where the laser has been pointed during the recording of the curves labelled as 'film day 122 ' in Figure 7. 
Remarkably, these two populations of spectra obtained from the film irradiated by room light only are clearly distinguishable in Figure 8c, where the Raman mapping of $799 \mathrm{~cm}^{-1}$ peak is displayed: the area where the biomass is abundant gives a stronger intensity, and this is a further confirmation that the far more intense signal of the black curve in Figure 7 is due to the biomass. On the other hand, the Raman mapping of the film exposed to solar light indicates a homogeneous surface, highlighting the absence of biomass in that surface, with a Raman spectrum which does not change with the area analysed, and a signal intensity far lower than the one given by the film with accumulated biomass.

The conclusive evidence that AquaSun inhibits the formation of biomass on the surface faced to solar light is given by SEM analysis (Figure 9, carried out with a FEI Nova NanoSEM 650 microscope). No relevant differences are observed in the glass coated with AquaSun at day $=0$ and after 122 days under the conditions of experiment B (Figures 9 a and 9 b, respectively). Conversely, the film exposed to room light after 122 days is significantly populated by biomass (Figure 9c). As with regards to the bare (unprotected) glass in experiment B, the SEM image (figure $9 \mathrm{~d}$ and inset) demonstrates the presence of microorganisms with a circular shape, closely resembling a planktonic diatom. 

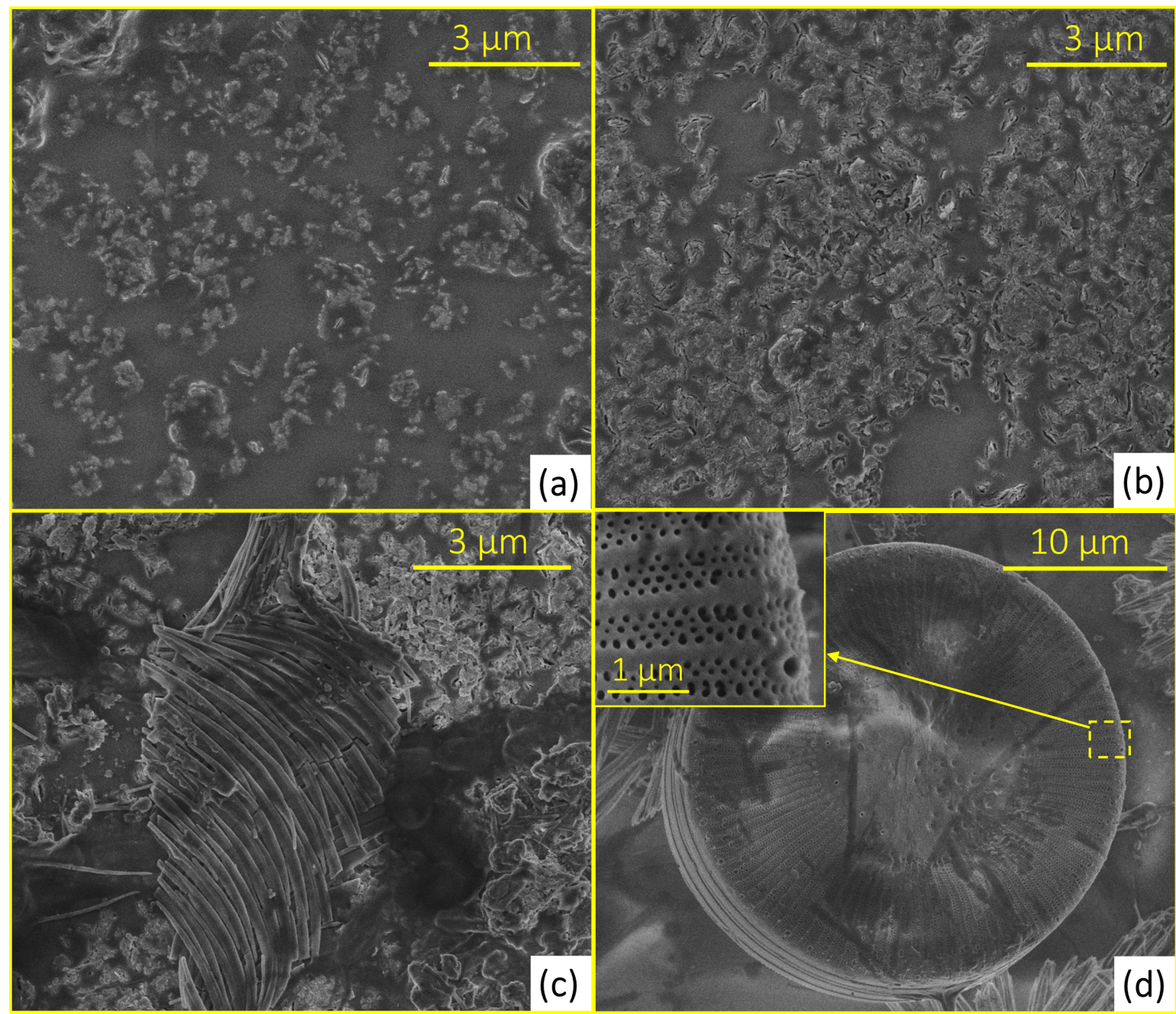

Figure 9. SEM images at 25ooox magnification of the functionalized glass at day o (a), after experiment $\mathbf{B}(\mathrm{b})$ and after experiment $\mathbf{A}(\mathbf{c})$; SEM image at 8ooox magnification of the bare glass after experiment $\mathbf{B}(\mathbf{d})$.

It is worth reminding that the photocatalytic reaction on the submarine surface is triggered by visible-light radiation which easily penetrates sea water, with reflection at moderate depths accounting to only 5 -ı $\%$, and with a negligible absorption."

To assist in the process for identifying alternatives to be used as substitutes to replace copper-based antifouling technology, which is of high environmental concern, we provide a brief insight on how the use of AquaSun 
ensures that copper is not being replaced with equal or more hazardous alternative, thereby getting ahead of new bans or restrictions. For example, phase out of copper-based anti-fouling paints on recreational vessels less than 65 feet in length by 2020 was adopted by the State of Washington, where salmon fisheries generate $\$ 3.18$ billion of economic activity each year supporting over 17 ,ooo jobs, with even 2 ppb levels of copper interfering with a salmon's its ability to avoid predators and also adversely impacts the ability of fish eggs and fry to develop normally. ${ }^{2}$

The components of the new antifouling product are $\mathrm{Bi}_{2} \mathrm{WO}_{6}$ and the encapsulant methylisica matrix. The only acute effect recorded in Material Safety Data Sheet for $\mathrm{Bi}_{2} \mathrm{WO}_{6}$ is moderate irritation of the respiratory system following inhalation, and low toxicity following ingestion due to its insoluble nature. The complete lack of solubility in water is most promising for what concerns its aquatic toxicity and ecotoxicity (persistance in the environment and bioaccumulation).

In general, bismuth is a heavy metal element with unusual low toxicity, obtained as a byproduct of extraction of other metals, including tungsten, used in many common stomach remedies and cosmetic products. ${ }^{13}$ Tungsten, in its turn, does not constitute an important health hazard. ${ }^{14}$ The tungstate anion $\mathrm{WO}_{4}^{2-}$ isomorph to molybdate, antagonizes the normal metabolic action of isomorph molybdate $\mathrm{MoO}_{4}^{2-}$ as metal carrier. Finally, the low cost, facile preparation with high purity, high stability in various electrolytes, and resistance to 
photocorrosion make $\mathrm{Bi}_{2} \mathrm{WO}_{6}$ ideally suited for application to photocatalytic wastewater treatment..$^{5}$

Sol-gel derived methylsilica is an eminent ORMOSIL. Due to their inertness and excellent textural properties, these materials are used as carriers for drugs and bioactive agents, ${ }^{16}$ with ORMOSIL nanoparticles generally being of little or no toxicity. ${ }^{17}$ Methyl-modified silica is highly stable in water and even more in seawater, whose $\mathrm{pH}$ is limited to the range 7.5 to 8.4 . Similar methylmodified silica coatings functionalized with silver ions are being considered for as antibacterial coatings on surgical-grade stainless steel. ${ }^{18}$

Being a waterborne xerogel organosilica coating, ${ }^{19}$ AquaSun is easily applied to all type of surfaces (steel, fiberglass, aluminum, wood etc.) by spraying or brushing eliminating the need to handle dangerous paint formulations (safe for workers), curing at room temperature. The high chemical and physical stability of antifouling sol-gel coatings generally affords minimum of two years protection, thereby reducing frequency of applications, while reducing drag to the smooth layer formed at the outer surface of the vessel. Forthcoming trials in the open sea will be aimed to identify the optimal application parameters for different vessels. The technology, indeed, is made available in open innovation regime with the aim to shorten time to the introduction of high performance, environmentally friendly antifouling coatings affording affording the economic advantages of efficient antifouling action, while protecting the aquatic environment and, ultimately, human health. 


\section{Conclusions}

The use of $\mathrm{Bi}_{2} \mathrm{WO}_{6}$ encapsulated in ORMOSIL (Aquasun) and deposited on glass has been proven effective in preventing the accumulation of biomass on glass in a real sea water environment in prolonged testing lasting up to four months. Extensive Raman mapping characterization of the coating using a glass surface as probe highlights the formation of biomass on selected areas of the glass when only diffuse visible light radiation reaches the surface, whereas unprotected glass was found covered with diatoms. Exposing the coating to visible light radiation using simulated solar light even for a few hours per day $(2.5,5$ and $8 \mathrm{~h}$ for $\mathrm{I22}$ consecutive days) at moderate $\mathrm{UV}$-vis radiation $\left(2.8\right.$ and $60 \mathrm{~W} / \mathrm{m}^{2}$ in the $\mathrm{UV}$ and visible regions, respectively), prevents the formation of any biofilm with a significant reduction in the total amounts of inorganic carbon in water and a concomitant increase of dissolved organic carbon due to ongoing photosynthesis. These results open the route to widespread application of the AquaSun for the protection of widely different surfaces constantly submerged in sea water.

\section{Acknowledgments}

This article is dedicated to Dr. Valerica Pandarus (SiliCiycle, Canada) on the joint occasion of to years of fruitful cooperation with two of us (RC and MP) and of her PhD from Laval University. Shadi W. Hasan (Masdar Institute of Science and Technology, Abu Dhabi) is acknowledged for enabling the use of the turbidimeter in his lab. We are grateful to Cyril Aubry (instructor at Masdar Institute of Science and Technology) for his precious assistance during SEM and Raman measurements. 


\section{References}

1. D. Williams, Challenges in developing antifouling coatings, IMarEST, London, 29 April 2010.

2. R. Ciriminna, F. V. Bright, M. Pagliaro, Ecofriendly Antifouling Marine Coatings, $A C S$ Sustainable Chem. Eng. 2015, 3, 559-565.

3. M. R. Detty, R. Ciriminna, F. V. Bright, M. Pagliaro, Environmentally Benign Sol-Gel Antifouling and Foul-Releasing Coatings, Acc. Chem. Res. 2014, 47, 678-687.

4. G. Scandura, R. Ciriminna, Y.-J. Xu, M. Pagliaro, G. Palmisano, Nanoflower-Like $\mathrm{Bi}_{2} \mathrm{WO}_{6}$ Encapsulated in ORMOSIL as a Novel Photocatalytic Antifouling and FoulRelease Coating, Chem. Eur. J. 2016, 22, 7063-7067.

5. R. Ciriminna, L. Albanese, F. Meneguzzo, M. Pagliaro, Hydrogen Peroxide: A Key Chemical for Today's Sustainable Development, ChemSusChem 2016, 9, 3374-3381.

6. S. Møller Olsen, J. B. Kristensen, B. S. Laursen, L. T. Pedersen, K. Dam-Johansen, S. Kiil, Antifouling effect of hydrogen peroxide release from enzymatic marine coatings: Exposure testing under equatorial and Mediterranean conditions, Prog. Org. Coat. 2010, 68, 248-257.

7. P. Falkowski, Ocean science: The power of plankton, Nature 2012, 483, S17-S20.

8. N. Zhang, R. Ciriminna, M. Pagliaro, Y.-J. Xu, Nanochemistry-derived $\mathrm{Bi}_{2} \mathrm{WO}_{6}$ nanostructures: towards production of sustainable chemicals and fuels induced by visible light, Chem. Soc. Rev. 2014, 43, 5276-5287.

9. S. Determann, J. M. Lobbes, R. Reuter, J. Rullkötter, Ultraviolet fluorescence excitation and emission spectroscopy of marine algae and bacteria, Mar. Chem. 1998, 62, 137-156.

10. A. Phuruangrat, P. Dumrongrojthanath, N. Ekthammathat, S. Thongtem, T. Thongtem, Hydrothermal Synthesis, Characterization, and Visible Light-Driven Photocatalytic Properties of Bi2WO6 Nanoplates, J. Nanomater. 2014, 1 (2014) Article ID 138561.

11. D. M. McMaster, S. M. Bennett, Y. Tang, J. A. Finlay, G. L. Kowalke, B. Nedved, F. V. Bright, M. E. Callow, J. A. Callow, D. E. Wendt, M. G. Hadfield, M. R. Detty, Antifouling character of 'active' hybrid xerogel coatings with sequestered catalysts for the activation of hydrogen peroxide, Biofouling 2009, 25, 21-33.

12. Washington State Legislature, Chapter 70.300 Recreational Water Vessels, Antifouling Paints, http://apps.leg.wa.gov/Rcw/default.aspx?cite=70.300\&full=true

13. J. Krüger, P. Winkler, E. Lüderitz, M. Lück, H. U. Wolf, Bismuth, Bismuth Alloys, and Bismuth Compounds, Ullmann's Encyclopedia of Industrial Chemistry, Wiley-VCH, Weinheim: 2003.

14. P. E. Leffler, G. Kazantzis, "Tungsten" In Handbook on the Toxicology of Metals, G. F. Nordberg, B. A. Fowler, M. Nordberg (Ed.s), $4^{\text {th }}$ edition, Elsevier: 2016; Chapter 58.

15. S. Girish Kumar, K. S. R. Koteswara Rao, Tungsten-based nanomaterials $\left(\mathrm{WO}_{3} \&\right.$ $\mathrm{Bi}_{2} \mathrm{WO}_{6}$ ): Modifications related to charge carrier transfer mechanisms and photocatalytic applications Appl. Surf. Sci. 2015, 355, 939-958.

16. I. Roy, P. Kumar, R. Kumar, T. Y. Ohulchanskyy, K.-T. Yong, P. N. Prasad, Ormosil nanoparticles as a sustained-release drug delivery vehicle, $R S C A d v$. 2014, 4, 53498-53504.

17. D. Kumar, C. K. Prashant, A. Kumar Dind, S. Mitra, "Toxicity assessment of Ormosil Nanoparticles" In Nano BioMaterials, V. Rajendran, P. Prabu, K. E. Geckeler (Ed.s), Bloomsbury Publishing India, New Delhi: 2014.

18. R. Procaccini, A. Bouchet, J. I. Pastore, C. Studdert, S. Ceré, S. Pellice, Silverfunctionalized methyl-silica hybrid materials as antibacterial coatings on surgical-grade stainless steel, Prog. Org. Coat. 2016, 97, 28-36. 
19. M. R. Detty, R. Ciriminna, F. V. Bright, M. Pagliaro, Xerogel Coatings Produced by the Sol-Gel Process as Anti-Fouling, Fouling-Release Surfaces: From Lab Bench to Commercial Reality, ChemNanoMat 2015, 1, 148-154. 